\title{
REFLECTIONS AND THOUGHTS ABOUT THE SOCIAL AND CULTURAL ROLE OF ALCOHOL
}

\author{
Natalia Struchkova, Aimar Ventsel
}

Mrs. Lasuria's age [is] close to 130 [...] She considered herself young until five years ago. She smokes one package of cigarettes daily and inhales, a habit she has had for sixty-two years. She drinks a glass of wine before her noon meal and each morning before breakfast a glass of vodka.

(Leaf 1975: 8)

This description of an old lady comes from a book by Alexander Leaf about his travels to seek, find, and understand the reasons for the longevity of centenarians (people over 100). The reading of the part dedicated to the then Soviet Caucasus region Abkhazia is especially amusing. It turns out that all of the centenarians he visited were relatively hearty drinkers. Most of the old people consumed wine daily and did not hesitate to enjoy a drink Leaf describes as 'Georgian vodka' but is, in fact, a homebrewed hard liquor mainly known as chacha, seldom containing less than sixty per cent of alcohol. All these people were respected community workers, still actively participating in physically heavy agricultural work but also travelling huge distances to visit friends, singing in village choirs, or looking after grandchildren. In many places the author goes into philosophical passages about the relation between health and alcohol consumed. Alexander Leaf, an educated middle-class American, comes from a different culture, from a culture where intensive alcohol consumption has been traditionally regarded as a problem, a symbol for the underclass, people who were often seen as 'non-humans'. Indeed, in Victorian England, poor people were seen as 'dirty' and morally deprived, which altogether made them another 'species' compared to their educated affluent co-citizens (Nayak 2003: 76-77). This perception about the lack of morals of poor people also included their imagined uncontrolled alcohol consumption. In the same time period in the USA, any kind of alcohol addiction, i.e. alcoholism, was seen as a particularity of the working classes - "Negroes, Catholics, Irish immigrants, and so on" (McDonald 1994a: 4). Wealthy and educated classes were seen as free from that 
evil. Moreover, while 'alcoholism' and 'addiction' were seen as 'mental illnesses' of the poor (Gusfield 1963), then affluent classes were proud of their 'abstinence', which was "closely tied in with Protestant notions of self-control" (McDonald 1994a: 2). This attitude helped to develop 'medical imperialism', seeing alcohol consumption as a problem and the consumers as deviant (Heather \& Robertson 1989: 146). Therefore, the surprise of Alexander Leaf about the 'normality' of constant wine drinking in Abkhazian villages could be understood.

On closer inspection, this surprise, however, is more than hypocritical. Western middle and upper classes do consume alcohol. As the historical research shows, there exists certain 'good drinking' based on a knowledge of and ability to choose and discuss 'good wines'. Such knowledge is the product of centuries-long cultural development, where the snobbish discussing of wine became a symbol of belonging to the elite (Shapin 2012). When snobbish and controlled alcohol consumption, or even tee-totality, is 'good drinking' in the Western society, then it is not necessarily the case with other societies. Ironically, both public perception and academics tend to associate and measure commitment to Islam with the non-drinking of alcoholic beverages. For example, there are even authors who measure religious radicalisation in Central Asia with the decreasing alcohol consumption (Rose 2002: 105). When Aimar Ventsel, one of the co-authors of this essay, told his Russian friend who knows Almaty, the capital of Kazakhstan, from the Soviet era, that during his three-week stay he saw only one drunken person in the streets of the city, and three times somebody walking around with a beer bottle in their hand (and that this was in sharp contrast with Astana, which is the centre of the 'Russified North'), his friend's reaction was: "This means Islamisation!" Here we see that for Western/European society alcohol consumption has always been controversial and multi-faceted.

Surprisingly, questions and problems surrounding 'eastern' drinking do not differ from 'western' drinking as much as one might wish to think. For Westerners Eastern Europe / Russia / Soviet Union have always been associated with spontaneous, enormous, and exotic alcohol consumption. However, at a closer look, controversies surrounding alcohol consumption in Western societies are not dissimilar. Let us take, for example, the (former) Soviet Union. The drinking of alcohol in the Soviet Union was seen as deviant (Dragadze 1994). However, people in the Soviet Union drank heavily, even in Islamic republics (Smith 1976). When 'Russian drinking' was considered the 'bad drinking', then Georgians from Caucasia accorded the term 'good drinking', doing it in a controlled way, combining it with ritualistic toasting (Dragadze 1994; Scott 2012). The Bolshevik/Communist enlightenment mission in Siberia had the ambition to bring 'culture' or kul'tura to the 'backward' peoples of the region. Habeck (2011: 65-66) theorises that the 'format of culture' helped to import European 
values into Soviet life. Apart from hygiene and illiteracy, the Bolsheviks were also concerned with fighting alcoholism. These values constitute the essence of kul'tura. The irony is that the Soviet state was built on and around alcohol: consuming alcohol was essential to the social life, as was the state monopoly on alcohol for the budget (Schrad 2014). All these controversies are also reflected in the historical development of the alcohol culture in the region in which we have both carried out fieldwork - the Republic of Sakha in the Russian Far East.

\section{THE MANY FACES OF VODKA IN THE REPUBLIC OF SAKHA (YAKUTIA)}

During the past few years, the consumption of alcoholic beverages in Yakutia has been in constant decline. This is confirmed by local medical institutions who argue that the number of alcoholics is slowly but constantly diminishing year after year.

Moreover, every person who knows the republic has also seen how alcohol is becoming less present at important public and private social events. Notwithstanding the fact that wines and vodka are still part of the traditional culture of celebration, getting drunk is increasingly unpopular. At weddings, funerals, and public events one sees that participants drink more modestly. This modesty is also accompanied by the decrease of alcohol-related criminality and criminality in general. The streets of the big cities in Yakutia are now relatively safe at night - something unimaginable ten years ago.

We would argue that this modesty is a logical result of a certain historical development and could have been forecasted a few years ago. But, in order to understand the changes in the consumption of alcoholic beverages in recent years, we should go back in history.

Alcohol was, of course, known to the Sakha. From the 17th century it was one of the main commodities for change and trade. Historically, vodka was a 'good product'; it was offered to especially dear guests and kept at home for their visits. This was probably related to the high price and complicated access to alcohol. Spirits were seen as part of one's wealth. In this period, only rich people were able to afford alcohol. This situation lasted for a relatively long time, until the 1950s. At this time alcohol became more easily available, also its price decreased.

In the 1960s, in Yakutia, the drinking of alcohol became a common practice in Sakha villages. Alcohol became even cheaper and more available. This period also marked the growth in personal wealth among the rural population. Simultaneously, in the 1960s and 1970s, the control over selling and consuming 
alcohol weakened. After the war, rural people started to be paid salaries in cash instead of earlier 'norm days', a token system to purchase food and goods in village shops. Drinking became a sign of success: in villages constant drinking was the sign of a good salary.

The state under the last leader of the Soviet Union, Mikhail Gorbachev, tried to change it and introduced several limits on the sale of alcohol, up to a total ban. Unfortunately, these regulations remained fruitless in Sakha villages and people continued to drink heavily. The only change was that the sale of alcohol moved from state-controlled village shops to private homes or tochkas.

The 1990s brought with them a radical change in state control, which almost vanished in the middle of the decade. The disappearance of state control was accompanied by an increase in the volumes of consumed alcohol, the growth of sheer alcoholism, and the beginning of drinking at an even younger age. In a country where drinking has traditionally been an everyday habit, the 1990s were catastrophic. Vodka was not only an object for trade and enrichment but also became part of a certain way of life. Things turned even worse when most enterprises ceased to pay salaries, and vodka often replaced money as an equivalent for payment. This was especially true for rural settlements.

This was a period of spontaneous anti-alcohol movements. One of the first groups that appeared was comprised of people who propagated so-called 'acculturated drinking'. These people were mainly urban Sakha intellectuals who organised social events, accompanied by alcohol, with the goal to teach people to drink modestly. Most of these social events went out of control and ended as average drinking parties. The courage of the proponents of 'acculturated drinking' is amazing; they did not give up and organised a series of events. When we tried to know more about the fate of that group, one informant told us: "They all became alcoholics."

Changes in Sakha drinking habits occurred, however, at the end of the 1990 s, with the political and economic stabilisation, and the state was able to pay more attention to vodka consumption. In 2000, the Republic of Sakha as the first region of the Russian Federation passed a law of the Healthy Ways of Life (zdorovyi obraz zhizni), which became the basis for further alcohol policy, a policy that supported local grassroots initiatives that fought alcoholism. The mentoring of 'problematic' families in which one or both parents abused alcohol was widespread. These families were put under surveillance not only by the local administration but also by the community. The formation of the community initiative became so strong that several settlements declared themselves 'dry' and banned any sale of alcohol.

Reasons for these new modesty and abstinence initiatives were the growth of wealth and the spread of private entrepreneurship and career orientation, 
combined with traditional strong kinship ties amongst the Sakha. The development of market economy and all-Russian entrepreneurship strengthened individual responsibility, career consciousness and the valuation of family ties and personal health. In such a situation, traditional Sakha kinship solidarity and the obligation to support relatives motivated young and old entrepreneurs to control their alcohol consumption in order to increase their wealth. In that period, the government of the Republic of Sakha started to pay more attention to its alcohol policy. In 2010 a fundamental law was passed that regulated trade in alcoholic beverages, a law that was causal in establishing new consumption patterns.

Access to alcoholic beverages was strictly limited from 2 to 8 p.m., with stricter age controls introduced. Apart from the state, several public figures began to propagate modesty and abstinence as a modern Sakha tradition. Alongside these developments, the popularity of alcohol consumption decreased among the ethnic Sakha, especially among young urban and rural intellectuals. Student life changed slowly but radically after 2010. Drinking became condemned by wider sections of the population and this concerned especially public drinking.

In the Republic of Sakha, alcohol consumption is still a problem, as is the illegal sale of vodka. The attitudes have, however, transformed. This is especially notable in the young intellectual and student circles. Once notorious urban criminals, Sakha students have become conscious career builders. Alcohol misuse is currently identified more with poor social groups than personal wealth.

This complex development is impossible to understand without an eye on social, economic and political development in the Republic of Sakha, including individual and group perspectives.

\section{REFLECTIONS}

The most important conclusion drawn from the workshop in 2013 was a horror story for all health freaks: alcohol is so deeply embedded in the social and cultural life of the Arctic that there is almost no way to live without it. Alcohol is a part of practically any social event, from meeting old friends to large national official celebrations. The deep intimate meaning of alcohol use was demonstrated by Eleanor Peers's talk about officials who were supposed to propagate teetotal national holidays but did not abstain from a glass or three to celebrate the same holidays in their family circle. The social and cultural meaning of alcohol, its ritual role and symbolically central place in celebrations of different degrees seems to be the only factor that unites all ethnic groups, ages, and sexes in the Arctic. As we discovered, even non-drinking is interpreted 
in terms of drinking: non-drinking is a juxtaposition to drinking, not an act in itself. As was shown by several talks, non-drinking in the Arctic is a political symbol or path to voluntary exclusion from social and religious life. The decision to fight against alcohol use and refuse to drink can be interpreted as the denial of the meaning of alcohol, an attempt to depart from the mainstream. As demonstrated by the abstinence movement among non-Russian people in the Russian Arctic, abstinence is related to identity and opposition to Russianness, and non-drinking has become a symbol for ethnic heritage.

The feedback from the first workshop dedicated to the cultural and social meaning of alcohol was surprisingly positive. Several colleagues expressed their appreciation announcing how such an academic event dedicated to alcohol use in Siberia was long overdue. Even stranger was the fact that the organisers had to struggle to find presenters, and encourage people to attend the conference. When talking about Siberianists, most of us have conducted fieldwork in Siberia for a decade or more, and in practice it means we have had to participate in numerous drinking parties, receptions, and just 'ordinary' events like birthday parties. In total we have consumed dozens of litres of pure alcohol with the accompanying consequences that occur the day after. However, these numerous litres of alcohol also mean that we know how alcohol is consumed and what rituals surround drinking. In fact, most of us are quite sophisticated and can distinguish between the rules, rituals, and norms concerned with when, where, and how glasses should be raised and emptied. Even stranger and more interesting was the reaction of people when they were invited to the workshop. The standard answer was: "I have never conducted research on alcohol use." At the same time, people could share their experiences of Siberian drinking habits in a more informal environment, for instance, in a pub. Seemingly, this reaction also demonstrates a lack of flexibility of social scientists, their fixation on their research agenda and topics formulated for their applications for funding. It also shows that we do not trust our experiences and we make use of only a small segment of the material we actually collect. This is a pity, because anthropologists' unique method of research anthropology - participant observation - supplies us with substantial knowledge of the cultures we spend a sizeable amount of time living with. We are all confronted with issues and topics that do not belong directly to our research agenda. As the previous alcohol workshop demonstrated, we can put these bits and pieces together in order to form a coherent story that helps us, and other people, to understand different cultures, ethnic and religious groups.

When skimming the English-language academic literature related to the social, medical, political, and cultural meaning of alcohol use, the absence of the Arctic becomes obvious. Typical are collections of academic articles written 
by Western scholars about Western societies (Holt 2006), in some rare cases Eastern European or tropical countries are added (Douglas 1987; McDonald 1994b). Our assumption is that what we were doing in Tartu was quite different. We tried to conceptualise Arctic drinking instead of just focusing on case studies (Koester 2003) or seeing alcohol use as a problem and a tragedy (Metzo 2009; Segal 1998; Segal et al. 1993). Most of the drinking-related research is very local, limited to a concrete community, religious group, ethnicity, and so on. Art Leete's talk showed that 'out there' exists a popular perception of regional drinking patterns. On the other side, by doing research in such an alcoholinfused region, we should further conceptualise our research methods. This was the reason why the paper by Briggs, Gololobov, and Ventsel was included in this special journal issue: there are moments when signed codes of research ethics fail to provide grounds or appear to be destructive for the research. The workshop offered an opportunity to bring the discussion to a new level, to start theorising on the concept of regional drinking. Of course, we can always fail, but this is the advantage of our more flexible workshop format - to become a basis for such discussions that probably do not fit into more regulated and strict conference agendas.

There is one more thing to address. People bring up plenty of topics when it comes to the discussion about drinking habits, but they often leave out one important factor, which is the state and national policy. It is obvious that the state has tremendous influence on alcohol use. As was demonstrated with the development of the alcohol culture in the Republic of Sakha, and currently all over the circumpolar region, the state heavily regulates alcohol sales. Moreover, the state interferes in drinking patterns usually through taxation to increase alcohol prices. The state punishes the abuse of alcohol and treats victims of alcoholism, as demonstrated by Argounova-Low and Sleptsov in this volume. It can be said that the state has its own interests in the quantities, and in where and when alcohol is consumed. Therefore, in the next workshop in 2014 we added presentations covering regions outside of the Arctic and discussed the state's role in drinking and non-drinking, comparing Arctic drinking and alcohol policy with these regions. We should not hesitate to do this more often because it gives us a fuller picture; and this way we can place our region within the context of more general debates. 


\section{REFERENCES}

Douglas, Mary (ed.) 1987. Constructive Drinking: Perspectives on Drink from Anthropology. Cambridge: Cambridge University Press.

Dragadze, Tamara 1994. Gender, Ethnicity and Alcohol in the Former Soviet Union. In: M. McDonald (ed.) Gender, Drink and Drugs. Oxford \& New York: Berg, pp. $145-152$.

Gusfield, Joseph R. 1963. Symbolic Crusade. Urbana, Ill.: University of Illinois Press. Habeck, Joachim Otto 2011. "Thank You for Being": Neighborhood, Ethno-Culture, and Social Recognition in the House of Culture. In: J.O. Habeck \& B. Donahoe (eds.) Reconstructing the House of Culture: Community, Self, and the Makings of Culture in Russia and Beyond. New York \& Oxford: Berghahn Books.

Heather, Nick \& Robertson, Ian 1989. Problem Drinking. Oxford: Oxford University Press.

Holt, Mack P. (ed.) 2006. Alcohol: A Social and Cultural History. Oxford \& New York: Berg.

Koester, David. 2003. Drink, Drank, Drunk: A Social-Political Grammar of Russian Drinking Practices in a Colonial Context. Anthropology of East Europe Review, Vol. 21, No. 2, pp. 41-46. Available at https://scholarworks.iu.edu/journals/index. php/aeer/issue/view/27, last accessed on June 5, 2015.

Leaf, Alexander 1975. Youth in Old Age. New York \& St. Louis \& San Francisco \& Mexico: McGraw-Hill Book Company.

McDonald, Maryon 1994a. Introduction: A Social-Anthropological View of Gender, Drink and Drugs. In: M. McDonald (ed.) Gender, Drink and Drugs. Oxford \& New York: Berg, pp. 1-31.

McDonald, Maryon (ed.) 1994b. Gender, Drink and Drugs. Oxford \& New York: Berg.

Metzo, Katherine 2009. The Social and Gendered Lives of Vodka in Rural Siberia. In: M.L. Caldwell (ed.) Food \& Everyday Life in the Postsocialist World. Bloomington \& Indianapolis: Indiana University Press, pp. 199-205.

Nayak, Anoop 2003. Race, Place and Globalization. Oxford \& New York: Berg.

Rose, Richard 2002. How Muslims View Democracy: Evidence from Central Asia. Journal of Democracy, Vol. 13, No. 4, pp. 102-111. http://dx.doi.org/10.1353/jod.2002.0078.

Schrad, Mark Lawrence 2014. Vodka Politics: Alcohol, Autocracy, and the Secret History of the Russian State. Oxford \& New York: Oxford University Press.

Scott, Eric R. 2012. Edible Ethnicity: How Georgian Cuisine Conquered the Soviet Table. Kritika: Explorations in Russian and Eurasian History, Vol. 13, No. 4, pp. 831-858.

Segal, Bernard 1998. Drinking and Drinking-Related Problems Among Alaska Natives. Alcohol Health and Research World, Vol. 22, No. 4, pp. 276-280. Available at http:// pubs.niaaa.nih.gov/publications/arh22-4/276.pdf, last accessed on June 5, 2015.

Segal, Bernard \& Duffi, Lawrence K. \& Avksentyuk, Alexi V. \& Thomasson, H.R. 1993. Biobehavioral Factors and Drinking among Alaskan and Siberian Natives: Cross Cultural Collaborative Research. Arctic Medical Research, Vol. 53, No. 2, pp. 568-572.

Shapin, Steven 2012. The Tastes of Wine: Towards a Cultural History. Wineworld: New Essays on Wine, Taste, Philosophy and Aesthetics, Vol. 51, No. 3, pp. 49-94. Available at http://www.people.fas.harvard.edu/ hsdept/bios/docs/shapin_Tastes_ of_Wine.pdf, last accessed on June 5, 2015.

Smith, Hedrick 1976. The Russians. New York: Ballantine Books. 